\title{
Evaluation of Non Steady Subsurface Drainage Equations for Heterogeneous Saline Soils: A Case Study
}

\begin{abstract}
A. K. Pali
Abstract:The present study aimed at investigating variability in drainable porosity and hydraulic conductivity of saline soils of Haryana state in India and evaluating various commonly used non steady subsurface drainage equations by incorporating the heterogeneity of the two soil drainage properties in them. The hydraulic heads corresponding to different drainage periods, predicted by these subsurface drainage equations were compared with the measured hydraulic heads for the same drainage periods. Amongst, Luthin and Worstell, Glover, Van Schilfgaarde, Modified Glover, and Integrated Hooghoudt equations, Van Schilfgaarde, Modified Glover, and Integrated Hooghoudt equations predicted the hydraulic heads quite close to the measured hydraulic heads. Luhhin and Worstellequation gave very lower hydraulic heads as compared to the measured ones and the deviation was from -5.32 to -64.35 per cent during 10 days of drainage period. Glover equation resulted in large positive per cent deviation (+4.25 to 30.64 per cent) in hydraulic heads in comparison to the measured hydraulic heads during 10 days drainage period. Hence, Van Schilfgaarde, Modified Glover, and Integrated Hooghoudt equations were considered to be appropriate equations for drainage design. Among these three equations, Modified Glover equation was the most superior followed by Integrated Hooghoudt equation and then Van Schilfgaarde equation.
\end{abstract}

Key words: Haryana; Hooghoudt; Glover; Van Schilfgaared, Luthin

\section{Introduction}

Historically, the main reason for drainage on agricultural land has been to enhance crop production. Drainage removes excess water from the soil and helps to create a well-aerated root environment that enhances plant uptake of nutrients. Drainage has been identified as the forgotten factor in sustaining irrigated agriculture (Scheumann and Freisem, 2001). Surface and subsurface drainage provide the following functions: protect the resource base for food production; sustain and increase yields and rural incomes; protect irrigation investment; protects lives and assets against flooding and high groundwater levels; provide improved health conditions; protect water quality. These seven functions encompass both subsurface and surface drainage. Drainage of agricultural soils allows timely field operations, and helps plant growth to begin early, continue vigorously, and achieve improved levels of productivity. Agricultural drainage improvements can be made on the soil surface, the subsurface, or a combination of both. Surface drainage is designed to remove standing water from the soil surface. It affects the water table by reducing the volume of water entering the soil profile. Subsurface drainage is generally assumed to be required whenever irrigated agriculture is practiced. Subsurface drainage is designed to remove excess water from the soil profile. The water table level is controlled through a series of drainage pipes (tile or tubing) that are installed below the soil surface, usually just below the root zone. The subsurface drainage network generally outlets to an open ditch or stream. For the same amount of treated acreage, subsurface drainage improvements are generally more expensive than surface drainage improvements. In states like Haryana and Punjab that depend heavily on irrigation from surface water supplies, subsurface drainage is often advised to prevent harmful buildup of salt in the root zone soil. Drainage benefits crop production by minimizing risks, improving efficiency, and increasing net income. With agricultural drainage, the continuing need for economical food production must be considered. Currently, research is focusing on methods that mitigate the adverse impacts of agricultural drainage. These techniques have the goal of sustaining agricultural productivity and profitability on existing cropland while addressing environmental problems. An important distinction must be made between improving drainage of land presently in agricultural production and converting additional wetlands. Present agricultural trends are toward intensive use of existing cropland, with much of the emphasis on new management technologies. Maintaining and improving existing drainage and associated yields on wet agricultural soils presently in production minimizes the economic need for landowners to convert wetlands.

The theory of flow of water in porous media and specifically for flow to drains has been developed over the years based on Bossinesq and Dupuit-Forcheimer theories. Most of the basic theory has been accepted and used as the basis for implementing designs for a subsurface drain system. Hooghoudt developed a steady state approach in the Netherlands that has been adopted for humid areas throughout the world (van der Ploeg et al., 1999). The drainage design in humid areas generally is based on the idea of a steady state system and the design criteria require the removable of a specified depth of water in a given period of time to ensure adequate 
aeration of the soil. In arid irrigated areas, rainfall is a minimal consideration in the design of a drainage system and the major source of excess water is a result of irrigation inefficiency Donnan developed a steady-state procedure for design of subsurface drainage in irrigated areas as well (USBR, 1993). Soil properties, successful design and implementation of subsurface drainage systems requires an accurate description of the soil properties including hydraulic conductivity, soil layers, soil types, saturated zones, and the specific yield of the soil. An accurate description of the saturated zone above the water table and the aeration status is critical in the design and potential management of a drainage system. The spatial variability of these parameters also represents a significant problem when considering the design of a system. Simple field testing for these parameters may not be adequate to characterize the variation in soil type, soil layering, hydraulic conductivity, salinity, and toxic elements.

Several other theories are available for the design of subsurface drainage system but practically little field information is available regarding the field performance of subsurface drainage systems in salt affected soils. It is therefore necessary to evaluate the field performance of the available subsurface drainage equations in salt affected soils to arrive at an appropriate drainage design equation under given set of field conditions. Many researchers have compared several drainage equations with their field performance data and found that variation exists between theoretically predicted results and field performance results. This variation may be due to the fact that the drainage equations developed so far treat the hydraulic conductivity and drainable porosity of the soil as constant for specific field conditions, but it has been observed that great heterogeneity usually exists in the two drainage properties of soil, especially in saline alluvium soils that have great influence on the field performance results.

In view of the above, the present study was undertaken with the specific objectives of developing relations between hydraulic conductivity and drainable porosity with soil depth to obtain their average values representing the soil profile properties. Also several transient subsurface drainage equations with the values of drainage properties as determined above, were evaluated by comparing the theoretical results with the field performance data measured at an existing subsurface drainage system installed by Haryana Land Development Corporation at village Mudlana in Sonepat district.

\section{Location of the Study Area}

\section{Materials And Methods}

The study village Mudlana is located about at a distance of about $29 \mathrm{~km}$ from Sonepat district in Haryana, at $29^{\circ} 10^{\prime \prime} \mathrm{N}$ latitude and $76^{\circ} 43^{\prime \prime} \mathrm{E}$ longitudes with an altitude of $226 \mathrm{~m}$ above mean sea level. The study area is nearly flat with gentle slope and forms a part of vast alluvial plain in the catchment of river Yamuna. The peripheral higher elevations form a closed basin which restricts the surface and subsurface natural drainage resulting in inundation of the area for a few weeks by Yamuna flood-waters during heavy rainfall periods.

\section{Climate Conditions}

The climate of the study area is subtropical semiarid with high evaporation rates. The area receives an average rainfall ranging from 500 to $600 \mathrm{~mm}, 83$ per cent of which pours down from July to September. From October to June end, the weather remains dry excepting for a few showers received from western depressions. Pan evaporation generally exceeds precipitation thought the year except in rainy season. High evaporation rates (114-170 mm per month) just after the rainy season cause accumulation of salts from saline groundwater, which usually remains high. The average annual evaporation is about $2086 \mathrm{~mm}$. The summer season is very hot and in winter temperature drops down to $3-4{ }^{0} \mathrm{C}$.

\section{Soil Conditions}

The study area represents inline saline and water logged soils of Indo-Gangetic plains. The soils are slightly heavier in nature. Surface $25 \mathrm{~cm}$ soils are compacted with bulk density of $1.75-1.78 \mathrm{~g} / \mathrm{cm}^{3}$ and in lower layers; it is about $1.55 \mathrm{~g} / \mathrm{cm}^{3}$. The soils chiefly contain chlorides and sulphate salts of $\mathrm{Na}, \mathrm{Ca}$ and $\mathrm{Mg}$. Due to predominance of sodium salts, The SAR of the soil solution is invariably high (69.9) in top $15 \mathrm{~cm}$ depth. The top $15 \mathrm{~cm}$ soil has a $\mathrm{pH}$ of 9, an $\mathrm{EC}_{\mathrm{e}}$ of $13.1 \mathrm{mmhos} / \mathrm{cm}$ and an ESP of 69.2. The soils have about 21 per cent clay, 17 per cent silt and 61 per cent sand, falling under textural class $S_{1}$.

\section{Groundwater Conditions}

The groundwater of the study area is highly saline with $\mathrm{EC}_{\mathrm{e}}$ up to $21.5 \mathrm{mmhos}-\mathrm{cm}^{-1}$, making it not fully fit for irrigation and drinking purpose. The water table almost reaches the ground surface during monsoon season and its recession begins from October to June falling to a depth of 1.5-2.0 m below ground surface in summer season. The rate of water table decline has a trend almost similar to the average evaporation rate from January to May. 


\section{Experimental Drainage System}

The existing subsurface drainage system is installed in sandy loam soils with three drain spacing as 50, 67 and $84 \mathrm{~m}$, each at a depth of $1.6 \mathrm{~m}$ below ground surface. The impermeable layer is situated at $3.4 \mathrm{~m}$ below drain centre. The internal diameter of lateral $1575 \mathrm{~mm}$ and that of collector drain is $140 \mathrm{~mm}$ with a total length of $310 \mathrm{~m}$. The drainage system has been installed at $1.6 \mathrm{~m}$ depth from ground surface. The present study was conducted on $50 \mathrm{~m}$ drain spacing only. The observation wells and piezometers were installed between lateral drains at an average depth of $2 \mathrm{~m}$ below ground surface to monitor hydraulic heads between the drains.

\section{Determination of Drainage Properties of Soil Drainable Porosity}

The drainable porosity of the soil is not usually a constant, but besides other things, it is a function of water table depth (Taylor, 1960) or in other words soil depth. The time of drawdown and shape of the water table depend on the particular way in which drainable porosity is related to water table depth. Thus, it is convenient and often necessary in drawdown studies to express drainable porosity as a function of water table depth. In the study, drainable porosity corresponding to different water table depths was determined from water table drawdown and drain discharge measurements at the experimental site and a functional relationship between drainable porosity and soil depth was developed. The relation is shown in Fig.2 and the relationship equation was found as given below.

$$
f=a Z^{b} \quad\left(r^{2}=0.970\right)-\cdots-----(1)
$$

Where, $\mathrm{Z}$ is soil depth in $\mathrm{m}$; ' $\mathrm{a}$ ' and ' $\mathrm{b}$ ' are regression coefficients $(\mathrm{a}=0.138014 ; \mathrm{b}=0.5505)$.

If we use an average constant value of drainable porosity, $f$, it must be representative of entire soil profile in which drainage water flows towards drains. Therefore, to arrive at an average value, eq. (1) can be integrated within limits $\mathrm{Z}=0$ to $\mathrm{Y}$, where $\mathrm{Y}$ is the depth of drain center from the ground surface, and divided by drain depth $Y$, which is assumed to be the flow region. Thus,

$$
\begin{aligned}
f & =\int_{0}^{Y} a Z^{b} \\
& =\left[a \frac{Z^{b+1}}{b+1}\right]_{0}^{Y} \\
& =a \frac{Y^{b+1}}{b+1}
\end{aligned}
$$

Dividing eq. (2) by drain depth $Y$ for obtaining average value of ' $\mathrm{f}$ ', we get,

$$
\begin{aligned}
& f_{\text {ave }}=\frac{a}{Y} \frac{Y^{b+1}}{b+1} \\
& =a \frac{Y^{b}}{b+1}
\end{aligned}
$$

\section{Hydraulic Conductivity}

The hydraulic conductivity values with respect to water table depths were determined by multiplying the corresponding values of hydraulic conductivity-drainable porosity (K/f) ratio values (as computed by the procedure given by Skaggs, 1976) with the above computed drainable porosity (f) values. The relation of hydraulic conductivity $(\mathrm{K})$ with soil depth was developed as shown in Fig. 3 and is expressed as follows.

$$
K=c Z^{d} \quad\left(r^{2}=0.975\right)------(4)
$$

Where, $Z$ is soil depth; 'c' and' $d$ ' are regression coefficients $(c=0.32296 ; d=-0.51)$.

Near soil surface it was found to be $0.96 \mathrm{~m} \mathrm{day}^{-1}$ and gradually decreased in lower soil layers. Apparently it looks that with increasing drainable porosity, the hydraulic conductivity must also increase. But, this is not the case here for saline soils, because the hydraulic conductivity is controlled by the relative distribution of different pore sizes in the soil mass not by the porosity alone. Thus in this case even with increasing $\mathrm{f}$ values, the $\mathrm{K}$ values for the lower depths were found to be low due to changing inherent nature of saline soils. The low hydraulic conductivity of lower soil layers caused the prolonged discharge flow from the drainage system as also observed during the operation of the drainage system.

By using the same procedure as described above, the average hydraulic conductivity can be obtained. Thus, integrating eq. (4) and dividing by $\mathrm{Y}$, average $\mathrm{K}$ is obtained as, 


$$
K_{a v e}=c \frac{Y^{d}}{d+1}
$$

\section{Evaluation of Subsurface Drainage Equations}

Using average values of drainable porosity (from eq. 3) and hydraulic conductivity (from eq. 5), the following transient subsurface drainage equations were evaluated by comparing the theoretical results of the equations with the field performance data measured at existing subsurface drainage installation commissioned at the study site. The geometry and symbols used in the following subsurface drainage equations are shown in Fig. 1 .

\section{Luthin and Worstell Equation}

\section{Drainage Equations Selected for Comparison}

The drain spacing values estimated by the developed equation (eq.14) were compared with those of estimated by the following selected subsurface drainage equations.

\section{(a) Luthin and Worstell Equation}

Luthin and Worstell (1959) suggested an unsteady subsurface drainage equation for elliptical shaped water table between drains as:

$$
S=\frac{4 c K t}{\pi f \ln \frac{h_{0}}{h}}
$$

In eq. (15), $\mathrm{c}$ is a constant representing the slope of line obtained by plotting the rate of flow into drains per unit length (q) as a function of $\mathrm{Kh}$ (hydraulic conductivity times the vertical distance from the drain to the water table midway between drains. Other parameters have been defined earlier.

\section{(b) Glover Equation}

Glover as reported by Dumm (1954) proposed the following drain spacing equation for homogeneous soils. The equation was developed by assuming an initially flat water table:

$$
S=\pi\left[\frac{K D_{a}}{f \ln \left(\frac{4 h_{0}}{\pi h}\right)}\right]^{1 / 2}
$$$$
\text { for }>\mathrm{D}>\mathrm{h}_{0}
$$

According to Dumm (1954), although Glover equation was developed under the assumption that $\mathrm{h}_{0}$ is small as compared to $\mathrm{D}$ but if one uses $\mathrm{D}_{\mathrm{a}}=\mathrm{D}+\mathrm{h}_{0} / 2$ or $\mathrm{D}_{\mathrm{a}}=\mathrm{d}_{\mathrm{e}}+\mathrm{h}_{0} / 2$ as the effective thickness of flow region, the equation will give a fairly satisfactory approximation even though the drains are placed at the bottom of the flow region.

\section{(c) Van Schilfgaarde Equation}

Van Schilfgaarde (1963) proposed an unsteady subsurface drainage equation, which corrected for DupuitForchheimer assumptions and avoided the assumption of a constant thickness of the flow region. The following equation was proposed:

$$
\begin{aligned}
S & =3 A\left[\frac{K\left(d_{e}+h\right)\left(d_{e}+h_{0}\right) t}{2 f\left(h_{0}-h\right)}\right]^{1 / 2} \\
\text { Where, } A & =\left[1-\left(\frac{d_{e}}{d_{e}+h_{0}}\right)^{2}\right]^{1 / 2}
\end{aligned}
$$

\section{(d) Modified Glover Equation}

Van Schilfgaarde (1965) extended the analysis of unsteady state drainage problem and modified the Glover equation to correct for convergence near drains. He assumed initially parabolic water table and depth of impermeable layer was not small. These assumptions were in contrast with those assumed by Glover. The following drainage equation was proposed: 
' $A$ ' is the same as in eq. (8).

$$
S=3 A\left[\frac{K t d_{e}}{f \frac{\ln h_{0}\left(2 d_{e}+h\right)}{h\left(2 d_{e}+h\right)}}\right]^{1 / 2}
$$

\section{(e) Integrated Hooghoudt Equation}

Bouwer and Van SchilfGaarde (1963) presented a simplified procedure for predicting the rate of fall of water table in tile drained or ditch drained land, bsed on steady state theory and abrupt drainage of pore space. They developed the following unsteady state drainage equation based on Hooghoudt steady state drainage equation:

$$
\frac{K t}{f}=\frac{C S^{2}}{8 d_{e}} \ln \frac{h_{0}\left(h+2 d_{e}\right)}{H\left(h_{0}+2 d_{e}\right)}
$$

Where, ' $\mathrm{C}$ ' is correction factor for using steady state solution of Hooghoudt and it generally varies between 0.8 and 1.0 for $0.02<\mathrm{h}_{0} / \mathrm{S}<0.08$, except for the first stages of water table recession following a ponded case $\left(\mathrm{h}_{0} / \mathrm{S}>0.015\right)$ where ' $\mathrm{C}$ ' is higher $(\mathrm{C}=1.1)$. The notations used in all above equations are defined in Fig. 1.

\section{Results And Discussion}

Variability of the Drainage Properties

The soil drainable porosity and hydraulic conductivity were determined from drain discharge and water table drawdown measurements. The procedures of their estimation offer the advantage of integrating the effects of spatial and depth-wise heterogeneity, which is usually observed in the two soil drainage properties and at the same time, provide the representative values for the entire soil profile through which water flows towards drains. In this study, it was found that a gradual variation in drainable porosity from 5.5 per cent for upper soil layers to 10.8 per cent for the deeper soil layers existed at the study area. The soil texture being sandy loam, the drainable porosity values corresponded well to the values in the range of 9 to 9 per cent for medium textured soils as reported by Dieleman and Trafford (1976). The low drainable porosity values near the soil surface may cause severe drainage problems leading to water logging conditions, because with lower values of drainable porosity, addition of even small amount of water in the soil in the form of rainfall or irrigation, may lead to large increase in water table height. Thus, it is necessary to determine the average drainable porosity of soil that incorporated spatial as well as depth-wise heterogeneity. The relation (Fig. 2 and eq.3) developed in the study for depth-wise variation of drainable porosity takes care of this heterogeneity. Similarly, great spatial and depthwise variation exists in hydraulic conductivity of soil. Thus, in order to account for this variability, the relation between hydraulic conductivity with soil depth was developed (Fig. 3 and eq. 5). It was observed that the hydraulic conductivity near soil was about $0.96 \mathrm{~m} /$ day and gradually went on decreasing reaching to $0.39 \mathrm{~m} / \mathrm{day}$ at the bottom of the soil's flow region. It is interesting to note that drainable porosity at upper soil layers is low, whereas the hydraulic conductivity of upper layers is high. Apparently, it looks that with increasing drainable porosity, the hydraulic conductivity should also be higher. But, the hydraulic conductivity is controlled by the relative distribution of different pore sizes in the soil mass. In this case, reverse situation in drainable porosity and hydraulic conductivity was observed because of changing inherent nature of saline soils. The low hydraulic conductivity values in lower soil layers cause prolonged discharge from the drains as also observed during the operation of the existing drainage system.

\section{Performance Evaluation of Drainage Equations}

As stated earlier, the average values of drainable porosity and hydraulic conductivity of the soil were computed from eq. (3) and Eq. (5), respectively for the soil profile flow region of $1.6 \mathrm{~m}$ measured from the ground surface as the drains were placed at $1.6 \mathrm{~m}$ depth below ground surface. The average value of drainable porosity was estimated as $0.11 \mathrm{~m}^{3} / \mathrm{m}^{3}$ and that of hydraulic conductivity as $0.518 \mathrm{~m} / \mathrm{day}$. These values were subsequently used in the drainage equations chosen for evaluation. Using observed water table drawdown at different periods and known values of other parameters $(S=50 \mathrm{~m}$; factor in Luthin and Worstell equation, $\mathrm{c}=1.2$, factor in Integrated Hooghoudt equation, $\mathrm{C}=0.8 ; \mathrm{D}=3.4 \mathrm{~m} ; \mathrm{d}_{\mathrm{e}}=2.5 \mathrm{~m} ; \mathrm{H}=\mathrm{h}+\mathrm{d}_{\mathrm{e}}$, where $\mathrm{h}$ is to be estimated; $\mathrm{h}_{0}=1.52$ $\left.\mathrm{m} ; \mathrm{D}_{\mathrm{a}}=\left(\mathrm{d}_{\mathrm{e}}+\mathrm{h}_{0}\right) / 2=3.26 \mathrm{~m} ; \mathrm{Y}=1.6 \mathrm{~m} ; \mathrm{A}=0.606\right)$, hydraulic heads (h) were calculated for comparison with the observed hydraulic heads. The predicted and observed hydraulic heads have been given in Table 1 and the variation of the predicted hydraulic heads is shown in Fig.-----. The percent deviation of predicted hydraulic heads from the observed ones is given in Table 2. 
From the above tables and Figure, it is seen that Glover equation (eq. 6) predicted almost distinctly low values of hydraulic heads throughout the entire period of drainage. After one day of drainage, Luthin and Worstell equation predicted 5.32 per cent less hydraulic head than the observed hydraulic head. Beyond first day, the per cent deviation rapidly increased beginning from -13.71 per cent at second day to -64.35 per cent at $10^{\text {th }}$ day of drainage. The average deviation of predicted hydraulic head in comparison to the observed hydraulic head was found as high as about - 38.1 per cent. This indicates that Luthin and Worstell equation is not at all reliable and may lead to distinctly under-design of subsurface drainage system in saline soils of Haryana. Glover equation (eq. 7) predicted higher values of hydraulic heads for entire drainage period in comparison to the observed heads. The per cent deviation of predicted hydraulic head after 1 day of drainage was found to be as high as 30.64 per cent as compared to the observed hydraulic head. From $2^{\text {nd }}$ day, the deviation went on gradually decreasing reaching to +4.25 per cent on only $10^{\text {th }}$ day. The average deviation per cent deviation was 18.9 per cent. This also suggests that if Glover equation is used for drainage design in saline soils, it will result in over design. Van Schilfgaarde equation (eq. 8) slightly higher hydraulics heads as compared to the observed hydraulic heads. The deviation of predicted heads was found to vary between +5.61 per cent and +9.5 per cent with an average value as 8.1 percent, indicating satisfactory field performance. Modified Glover equation (eq. 9) also showed reliable field performance. It resulted in only 3.45 per cent higher hydraulic head after $1^{\text {st }}$ day of drainage. During 1 to 4 days of drainage period, the average deviation of predicted hydraulic head was found +2.56 per cent only. From $5^{\text {th }}$ day onwards, it began predicting slightly lesser values of hydraulic head with a deviation varying between -1.52 and -10.89 per cent on $10^{\text {th }}$ day and the average deviation during this period was found to be about -6.07 per cent. The average deviation of predicted hydraulic heads during the entire period of drainage was only -2.62 per cent in comparison to the observed hydraulic heads, indicating a higher reliability of the formula for drainage design. Integrated Hooghoudt equation (eq. 10) gave slightly higher values of hydraulic heads than the observed values during initial 3 days of drawdown, but afterwards the equation predicted lesser hydraulic heads than the observed ones that ranged from -1.16 to -15.74 per cent. The average deviation during the entire period of 10 days was found as -5.32 per cent only.

\section{Conclusions}

If the average deviation of predicted hydraulic heads from the observed hydraulic heads as \pm 10 per cent is assumed to be acceptable, Van Schilfgaarde, Modified Glover and Integrated Hooghoudt equations predict the hydraulic heads within \pm 10 per cent range of variation and among these, Modified Glover equation is the most superior followed by Integrated Hooghoudt equation and then Van Schilfgaarde equation. As the variation in predicted hydraulic heads by Luthin and Worstell equation and Glover equation was significantly beyond \pm 10 , it can be out rightly discarded for drainage design in saline soils of Haryana.

\section{References}

[1]. Bouwer, H. and Van SchilfGaarde, J. (1963) Simplified method of predicting fall of water table in drained land. Trans. ASAE, 6(4): 288-296

[2]. Dieleman, P.J. and Trafford, B.D. (1976) Drainage testing. Irrigation and Drainage Paper No. 28, FAO, Rome

[3]. Dumm, L.D. (1954) Drain spacing formulas- new formula for determining depth and spacing of subsurface drains in irrigated land. Agril. Engg. ASAE, 35:726-730.

[4]. Luthin, J.N. and Worstell, R.V. (1959) The falling water table in tile drainage: III Factors affecting the rate of fall. Trans. ASAE, 2(1): $45-47 \& 51$.

[5]. Pali, A.K. (1986) Water table recession in relation to drainage properties of saline soils. Unpublished M. Tech. (Agril. Engg.) thesis, College of Agril. Engg, Sukhadia University, Udaipur, Rajasthan, India

[6]. Skaggs, R.W. (1977) Determination of the hydraulic conductivity-drainable porosity ratio from water table measurements. Trans. ASAE, 19: 73-80

[7]. Taylor, G.S. (1960) Drainable porosity evaluation from outflow measurements and its use in drawdown equations. Soil. Science, 90:38-345

[8]. Van Schilfgaarde, J. (1963) Design of tile drainage for falling water tables. J. Irrig. and Drain. Div. ASCE, 89(IR-2): 1-13

[9]. Van Schilfgaarde, J. (1965) Transient design of drainage system. J. Irrig. and Drain. Div. ASCE, 91(IR-3): 9-22

[10]. USBR (1993) Drainage Manual, United States Bureau of Reclamation, USA 


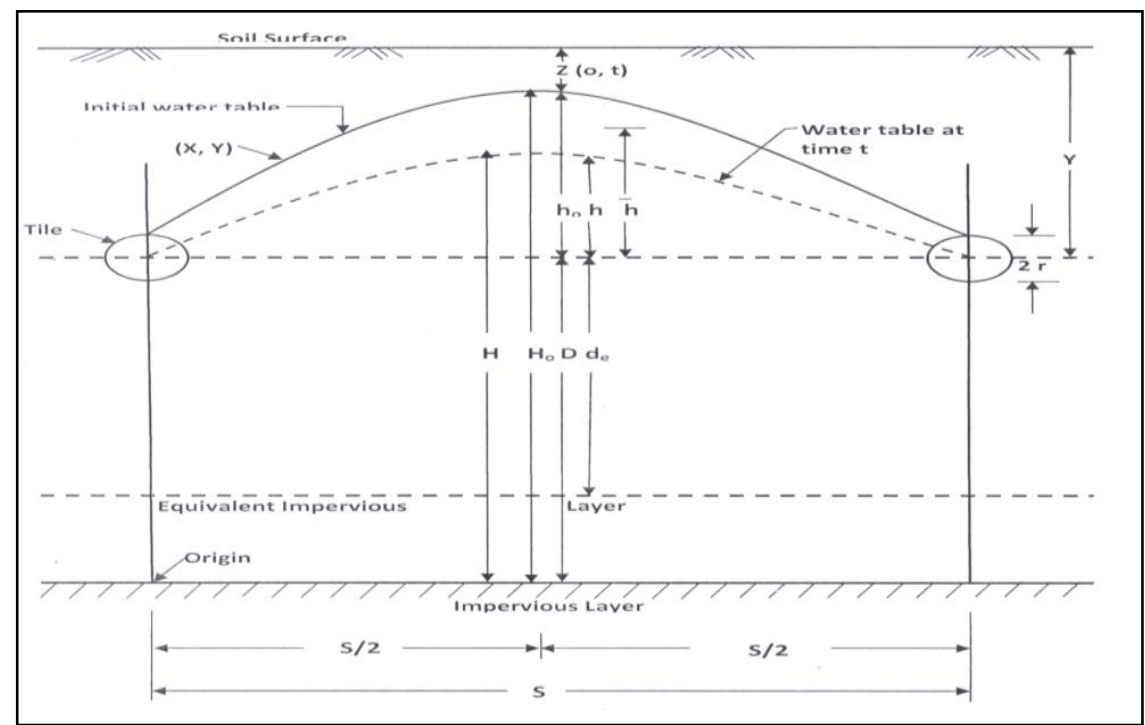

Fig 1 Geometry and symbols used in subsurface drainage equations

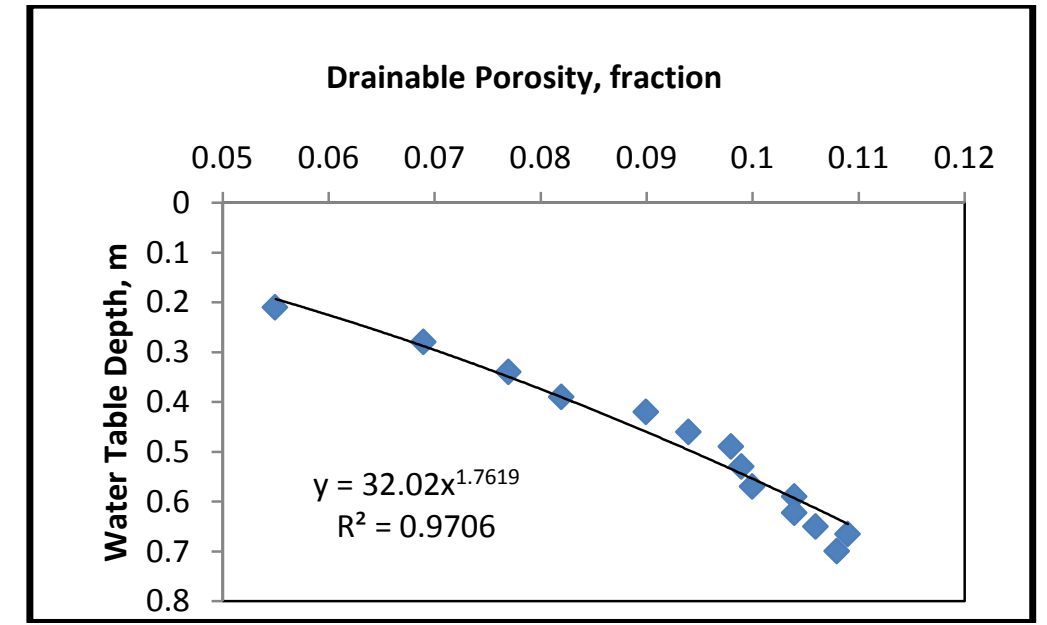

Fig. 2 Variation of Drainable Porosity with Water Table depth

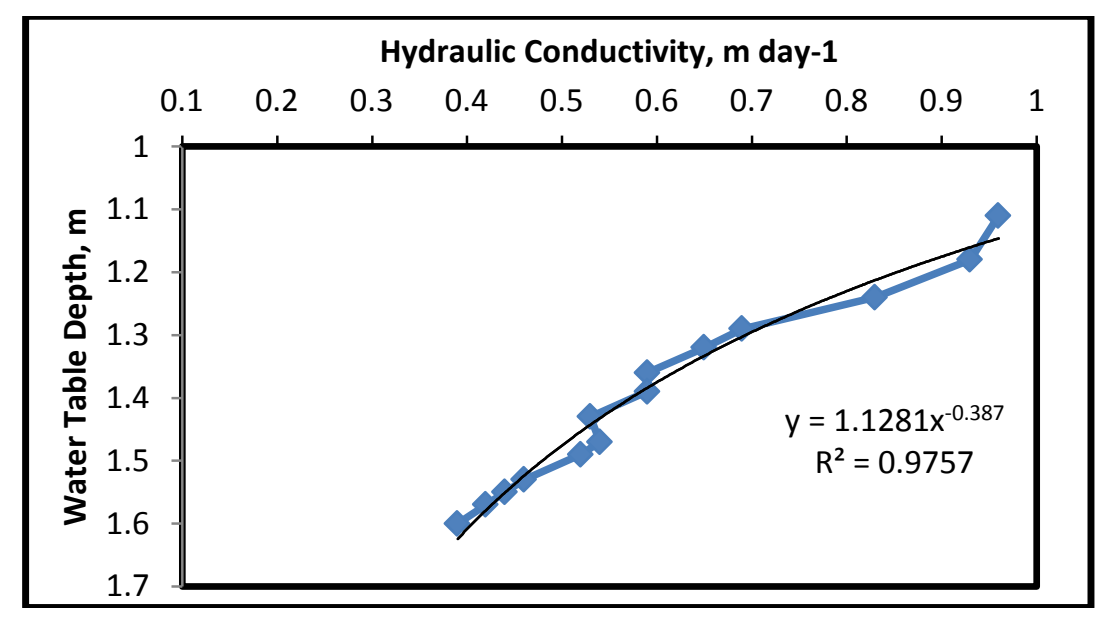

Fig. 3 Variation of Hydraulic Conductivity with Water Table Depth 


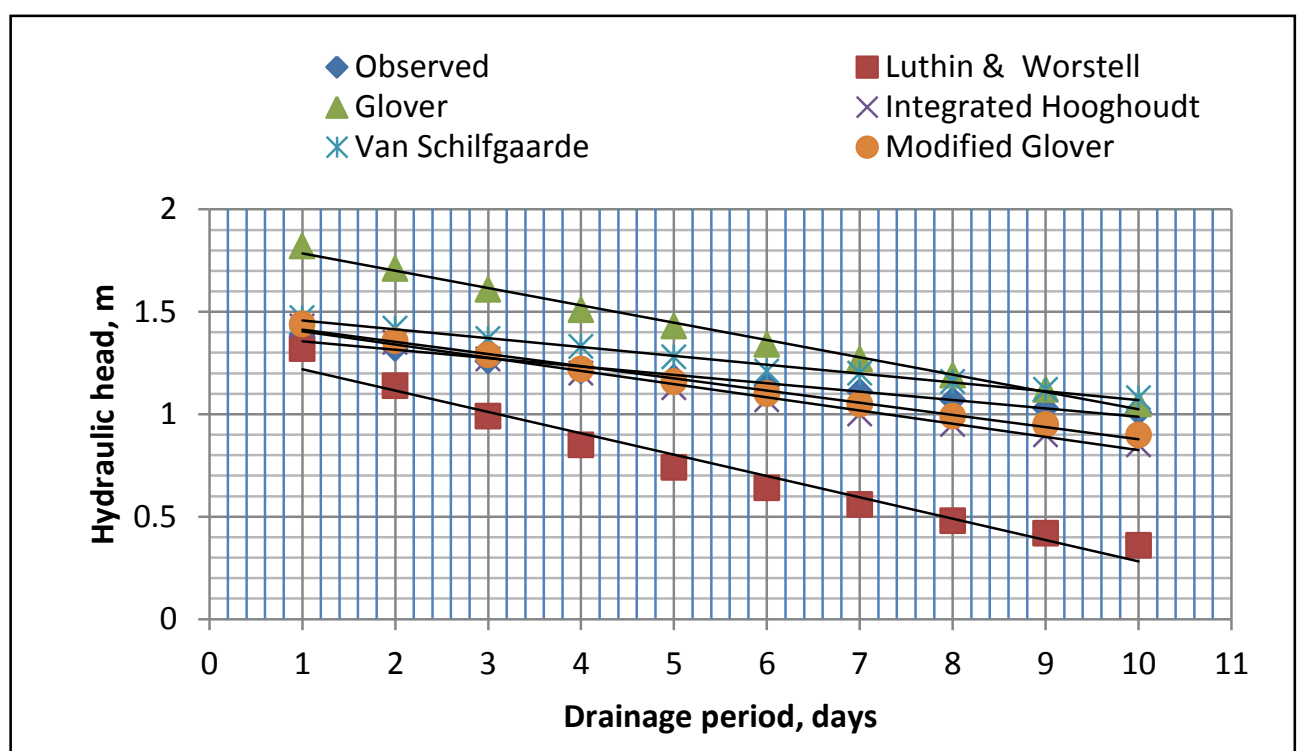

Table 1 Per cent deviation of predicted hydraulic heads from the measured hydraulic heads

\begin{tabular}{|c|c|c|c|c|c|}
\hline \multirow{2}{*}{$\begin{array}{l}\text { Drainage } \\
\text { period }\end{array}$} & \multicolumn{5}{|c|}{ Deviation from the measured hydraulic heads } \\
\cline { 2 - 6 } & $\begin{array}{l}\text { Glover } \\
\text { equation }\end{array}$ & $\begin{array}{l}\text { Integrated } \\
\text { Hooghoudt } \\
\text { equation }\end{array}$ & $\begin{array}{l}\text { Van Schilfgaarde } \\
\text { equation }\end{array}$ & $\begin{array}{l}\text { Modified Glover } \\
\text { equation }\end{array}$ & $\begin{array}{l}\text { Luthin and } \\
\text { Worstell } \\
\text { equation }\end{array}$ \\
\hline 1 & +30.64 & +2.87 & +5.61 & +3.45 & -5.32 \\
\hline 2 & +29.54 & +1.96 & +7.42 & +3.18 & -13.71 \\
\hline 3 & +27.69 & +0.63 & +8.81 & +2.46 & -21.66 \\
\hline 4 & +25.12 & -1.16 & +9.50 & +1.15 & -15.42 \\
\hline 5 & +20.76 & -4.32 & +8.56 & -1.52 & -43.77 \\
\hline 6 & +17.63 & -6.49 & +8.68 & -3.24 & -50.00 \\
\hline 7 & +13.78 & -9.28 & +7.93 & -7.01 & -55.51 \\
\hline 8 & +11.02 & -11.03 & +8.31 & -8.15 & -59.61 \\
\hline 9 & +8.54 & -12.62 & +8.83 & -10.89 & -64.35 \\
\hline 10 & 4.25 & -15.74 & +7.32 & & \\
\hline
\end{tabular}

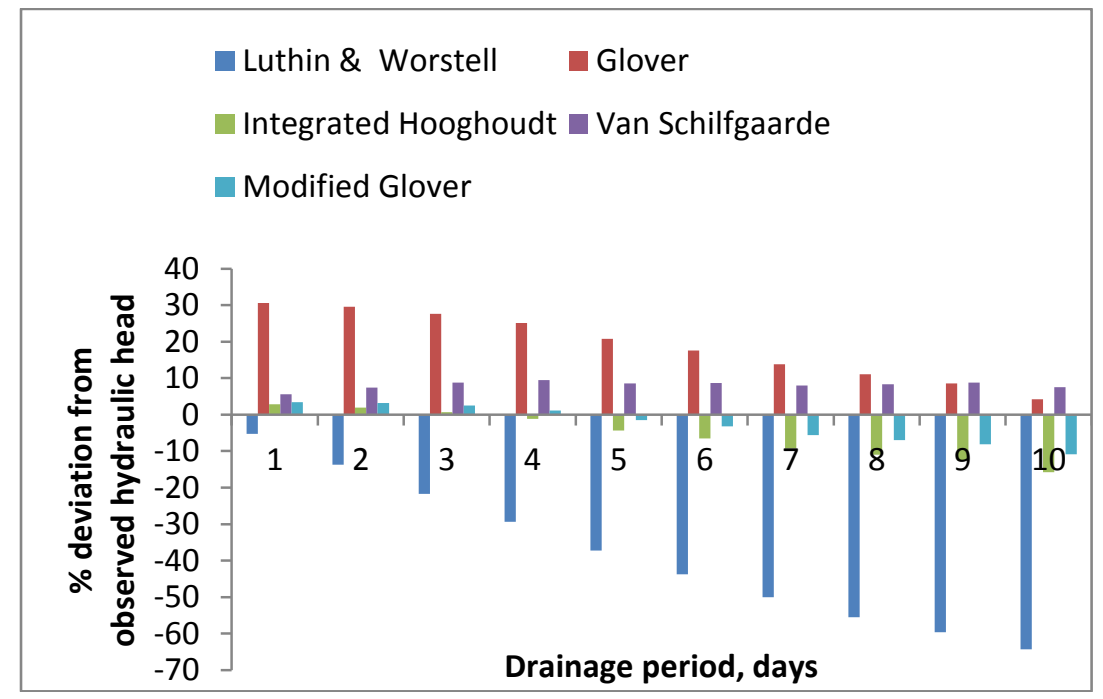

Fig. 5 Deviation of hydraulic heads predicted $s$ by drainageequations from observed hydraulicheads 